\title{
Experimental Study on Water-Jet Shock Microforming Process Using Different Incident Pressures
}

\author{
James Kwasi Quaisie $\mathbb{D}^{1},{ }^{1}$ Wang Yun $\left(\mathbb{D},{ }^{1}\right.$ Xu Zhenying, ${ }^{1}$ Yu Chao, ${ }^{1}$ Fuzhu Li, ${ }^{1}$ Philip Baidoo, \\ Joseph Sekyi-Ansah, ${ }^{1}$ and Emmanuel Asamoah ${ }^{1}$
}

${ }^{1}$ School of Mechanical Engineering, Jiangsu University, Zhenjiang, Jiangsu 212013, China

${ }^{2}$ Faculty of Technology, University of Education Winneba, Kumasi 00233, Ghana

Correspondence should be addressed to Wang Yun; wangyun@ujs.edu.cn

Received 1 March 2020; Revised 30 April 2020; Accepted 12 May 2020; Published 9 July 2020

Academic Editor: Jose Cesar de Sa

Copyright ( 92020 James Kwasi Quaisie et al. This is an open access article distributed under the Creative Commons Attribution License, which permits unrestricted use, distribution, and reproduction in any medium, provided the original work is properly cited.

\begin{abstract}
The purpose of this paper is to demonstrate a new process technology using the cavitation phenomenon, mainly a water-jet shock microforming, for the fabrication of a metallic foil. 304 stainless steel was exposed to a high-speed submerged water jet with different incident pressures and certain working conditions. In this experiment, a KEYENCE VHX-1000C digital microscope, confocal laser-scanning microscope (Axio CSM 700), and micro-Vickers hardness tester were utilized to observe the forming depth, surface quality, thickness distribution, and section hardness distributions under different incident pressures. The experimental results indicated that the surface morphology of the metal foils attained good geometrical features under this dynamic microforming method and there were no cracks or fracture. The forming depth and surface roughness increased with the incident pressure. In addition, the forming depth increased from $124.7 \mu \mathrm{m}$ to $327.8 \mu \mathrm{m}$, while the surface roughness also increased from $0.685 \mu \mathrm{m}$ to $1.159 \mu \mathrm{m}$ at an incident pressure of $8 \mathrm{MPa}$ to $20 \mathrm{MPa}$. Maximum thickness thinning of the formed foils occurred at the fillet region when the thickness thinning ratio was $21.27 \%$ under the incident pressure of $20 \mathrm{MPa}$, and there was no fracture at the bottom or the fillet region. The tested hardness indicated that during the cold-rolled state of the sample, the hardness sample increased slightly along the cross section of the formed region and the hardness of the annealed 304 stainless steel foils increased significantly along the cross-sectional region.
\end{abstract}

\section{Introduction}

The advancement of microforming technology has contributed tremendously to improve the quality production of microparts [1]. Therefore, active research on the field of microforming processes continues as industry players strive to further explore various efficient and cost-effective microforming technologies, towards achieving the production of better quality and affordable products [2]. The microforming yet depends seriously on testing over the trial and error approach due to strain rate, temperatures, and strain, and this requires high-capacity machines to realize satisfactory results, which consequently elevates the cost of production [3]. In recent years, various techniques have been comprehensively studied on microforming for the fabrication of microparts. In this research, we focus on the positive applications of engineering and discuss the turnaround point of water-jet cavitation technology [4]. Waterjet technology is a kind of cold-working technique, which has been applied in many engineering fields such as machinery, architecture, and civil engineering [5]. In this process, there is a discharge of high-pressure water from a nozzle immersed in the water and this has been widely utilized to study the flows of a water jet and the development of new applications [6]. There are various water-jet processing techniques including cavitating jet in air [7], waterjet peening [8], and cavitation of multifunction [9].

Chen et al. [10] conducted a study on the influence of water-jet peening on strengthening surface properties of the aluminum alloy 7075-T651 with a high pressure. Their study 
confirmed that after the water-jet peening (WJP), the sample fatigue life improved by $22 \%$ and $6.6 \%$, respectively, as compared with the shot peening (SP) and nonpeening. In addition, the fatigue life of the water-jet-peened sample increased much better than the shot peening during the introduction of the residual compressive stress near the strengthening surface. Finally, the water jet peened provided a good and better surface roughness strengthening than that of the shot peened, because the profile of the surface of the WJP was well protected and surface quality insured long fatigue life. Azhari et al. [11] studied the impacts of water jet peening on the surface features using carbon steel 1045 . Their result indicated that the hardness values were virtually similar to the base material even though the hardness value was changed up to a depth of $200 \mu \mathrm{m}$. In addition, at the initial stage, the damage characteristics consist of several fracture mechanism modes occurred. Srivastava et al. [12] investigated on the impacts of pulsating of water jets as a surface treatment method applying flat and circular nozzles by AISI 304 stainless steel surface. Their experimental results revealed that the pulsating water jet is a new possible technology for AISI 304 stainless steel surface treatment processes. It was also discovered that the original tensile residual stress was immediately changed to a compressive residual stress when relieved. Barriuso et al. [13] conducted a comparative study of water jets of titanium alloy (Ti6A14V) and the AISI 316 LVM material without using abrasive substance. Their results indicated that the titanium alloy developed no microstructural gradient or hardness, and in the AISI 316 LVM material, loss of volume occurred through the subsurface hardening, formation of cracks, erosion, and embrittlement. Azhari et al. [14] had studied on impact of WJP on AL-5005. Their study revealed that parameters such as feed rate, standoff distance (low or high), incident pressure, and number of passes have significant impact on the hardness and surface roughness of the material. Hashimoto et al. [15] conducted an investigation using WJP to improve the stability of residual stress during working processes. The results concluded that relaxation slightly occurred in the compressive residual stress, because of the restoration of the severe plastic deformation. Naito et al. [16] demonstrated a technique utilizing shots accelerated by a high-pressure WJ to be used as risk-free treatment in plants on stainless steel, and their results showed that the introduction of compressive residual was up to a depth of $600 \mu \mathrm{m}$. This indicated that the fatigue strength could be increased to $25 \%$ as compared to the surface not peened. Farayibi et al. [17] proposed a new surface modification method of laser clad of titanium alloy by pulse electron beam irradiation and using plain water jets. It was specified that complex geometries were achieved through these surface modification techniques. In addition, small distortion was produced on the plain water jet and this got increased as the number of passes increased.

The purpose of this study demonstrates the cavitation water-jet shock microforming process, where complex microparts can be formed with good quality using the different incident pressures and a microdie. Here, cavitation water-jet technology (CWJ) was used as a source of forming energy on the material surface for the plastic deformation, utilizing a high-speed underwater cavitation jet in a transparent tank filled with water. A series of experiments were conducted on 304 stainless steel foils to study the influence of incident pressures on surface morphology, forming depth, surface quality, thickness distribution, and the microhardness of the formed components.

\section{Materials and Methods}

2.1. Experimental Material. In this study, cold-rolled 304 stainless steel foils were selected as the experimental material because of their perfection mechanical properties and corrosion resistance. Thus, the thickness of the 304 stainless steel foils was $100 \mu \mathrm{m}$ which were cut into squares of dimensions of $50 \mathrm{~mm} \times 50 \mathrm{~mm}$ for the possibility of this experiment. The cut foil squares were cleaned from dirt with anhydrous alcohol. Then, the surfaces of the 304 stainless steel foil squares were wiped off by the residual liquid. The mask was placed on the material and firmly clamped against the material with a locking block. Tables 1 and 2 show the chemical compositions and mechanical properties of the 304 stainless steel foils.

2.2. Experimental Setup. The experimental setup of the water-jet cavitation shock microforming is shown in Figure 1(a). Tap water was stored for 18 hours in a larger tank of the size $2.5 \mathrm{~m} \times 2 \mathrm{~m} \times 1.5 \mathrm{~m}$, with a reasonable temperature of $25 \pm 5^{\circ} \mathrm{C}$ before the test. The experimental procedures were carried out using a transparent water tank with dimensions of $800 \mathrm{~mm}$ height with a cross-sectional area of $400 \mathrm{~mm} \times 400 \mathrm{~mm}$ square. For the purpose of visualization flow, the tank is made of acrylic resin. The nozzle used in this experiment was designed with reference to the angular nozzle for generating the periodic behavior of the cavitating water jets as shown in Figure 1(b). The optimum size ratio is $\mathrm{d}: L=1: 8$, where the throat diameter $d$ of the nozzle is $1.5 \mathrm{~mm}$, the throat length $L$ is $12 \mathrm{~mm}$, and the expansion angle $\theta$ is $30^{\circ}$. Note that the nozzle was located $150 \mathrm{~mm}$ deep from the water surface and the flow through the nozzle was driven using the plunger pump to generate the submerged cavitating water jets in the high-pressure test cell. The entire forming device was fixed on a platform and located in the water-filled transparent water tank. The standoff distance $S$ is defined as the distance between the nozzle outlet and the surface of the specimen under the test. In the present experiment, the standoff distance $S$ was fixed at $110 \mathrm{~mm}$. Inside the test cell, the forming device was placed perpendicularly to the cavitating water jet. The axial spacing $S_{L}$ between the microdie cavity and the jet axis was fixed at $10 \mathrm{~mm}$, so that the forming feature was located on the cavitation ring.

The cavitation number $\sigma$, which is a key parameter for a cavitating flow, is defined as a measure of the resistance of the flow to cavitation [18]. In nozzles, the flow velocity depends on the pressure difference between upstream and downstream pressures. Hence, the cavitation number $\sigma$ is given by 
TABLE 1: Chemical composition of 304 stainless steel.

\begin{tabular}{lccccccc}
\hline Element & $\mathrm{C}$ & $\mathrm{Mn}$ & $\mathrm{P}$ & $\mathrm{S}$ & $\mathrm{Si}$ & $\mathrm{Cr}$ & $\mathrm{Ni}$ \\
\hline Wt $(\%)$ & $\leq 0.8$ & $\leq 2.0$ & $\leq 0.045$ & $\leq 0.03$ & $\leq 1.0$ & $\leq 18.0$ & $\leq 8.0$ \\
\hline
\end{tabular}

TABLE 2: Mechanical properties of 304 stainless steel.

\begin{tabular}{lcccc}
\hline Elastic modulus $(\mathrm{GPa})$ & Poisson ratio & Yield strength $(\mathrm{MPa})$ & Tensile strength $(\mathrm{MPa})$ & Elongation $(\%)$ \\
\hline 194 & 0.3 & $\geq 205$ & $\geq 520$ & $\leq 40$ \\
\hline
\end{tabular}

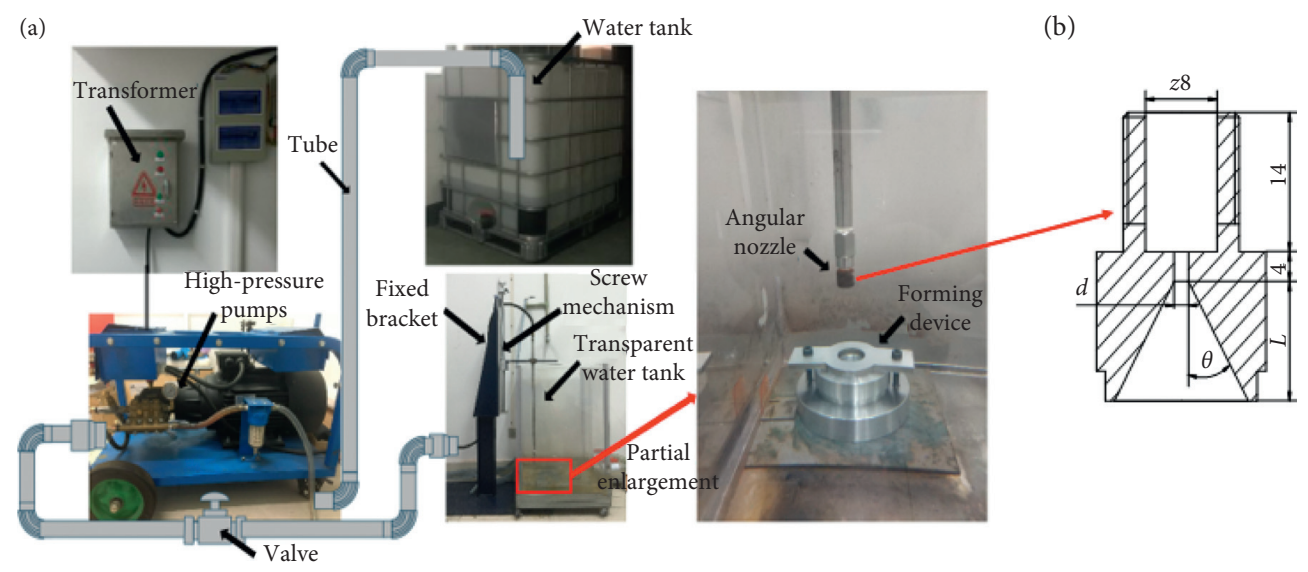

FIGURE 1: (a) Water-jet cavitation shock microforming experimental system; (b) nozzle geometry diagram.

$$
\sigma=\frac{p_{2}}{p_{1}}
$$

where $P_{1}$ is the incident (upstream) pressures and $P_{2}$ is the downstream pressures. Incident pressure is one of the key parameters in the process of water-jet cavitation shock microforming. The incident pressure $P_{1}$ was set as $8,12,16$, and $20 \mathrm{MPa}$ while the downstream pressure $P_{2}$ kept constant at $0.1 \mathrm{MPa}$; thus, the cavitation number $\sigma=0.0125,0.0083$, 0.0063 , and 0.005 . The test duration $t$ was 5 minutes, and five samples were tested under each incident pressure.

2.3. Microdie. In the micro-forming technique using waterjet cavitation shock, the microdie plays a very significant role in the forming process. Therefore, the microforming die was designed to reduce the effect of air resistance of the water-jet cavitation shock microforming as shown in Figure 2. In addition, the surface of the microdie should meet a certain standard of hardness and rust resistance during the water-jet cavitation shock process. In order to achieve this experimental process, the 304 stainless steel microdie material was selected. The contour size of the microdie was $40 \mathrm{~mm} \times 5 \mathrm{~mm}$, with a cavity depth of $3 \mathrm{~mm}$ and a diameter of $1.2 \mathrm{~mm}$. The 304 stainless steel microdie was manufactured with microelectric discharge machining (MICROEDM). The die was immersed in an anhydrous alcohol solution for ultrasonic vibration cleaning. After the process, a digital microscopy (KEYENCE VHX-1000C) was used for the measurement. The actual diameter of the microdie cavity was $1205 \mu \mathrm{m}$.
2.4. Forming Mechanism. The water-jet cavitation shock forming system consists of a piston pump, filter, regulating valve, pressure device, regulating device, nozzle, transparent tank, and forming device as shown in Figure 3(a). The forming device is fixed on the platform. The forming device is composed of a locking block, mask, seal ring, sample material, and microdie as shown in Figure 3(b). First, the foil was placed on the top of the die, covering the die openings completely. The flatness of the foil should be guaranteed. Secondly, the mask was placed on the foil and the mask and the microdie have the same axial hole at the center. Lastly, to avoid material wrinkling, the initial interface between the foil and the microdie is very crucial, so the two surfaces should be firmly attached to each other by a locking block. Besides, in order to provide an effective sealing, a seal ring was applied between the mask and the foil. During this process cavitation bubbles are generated by injecting a highspeed water jet through a nozzle into a chamber filled with water. When the cavitation bubbles approach the surface of the material, the sudden increase of local pressure due to the huge turbulent pressure pulsation causes their collapsing which generates shock waves [19]. These shock waves act on the surface of the workpiece and propagate into the interior of the workpiece, due to the high concentration of energy (the peak value of the collapse pressure reaches the gigapascal (GPa) range) [20]. The peak stress of the shock wave decreases as a shock wave propagates deeper into the sample material. When the peak value of the collapse pressure exceeds the Hugoniot elastic limit (HEL) of the material, it yields and deforms plastically. The plastic deformation of the 


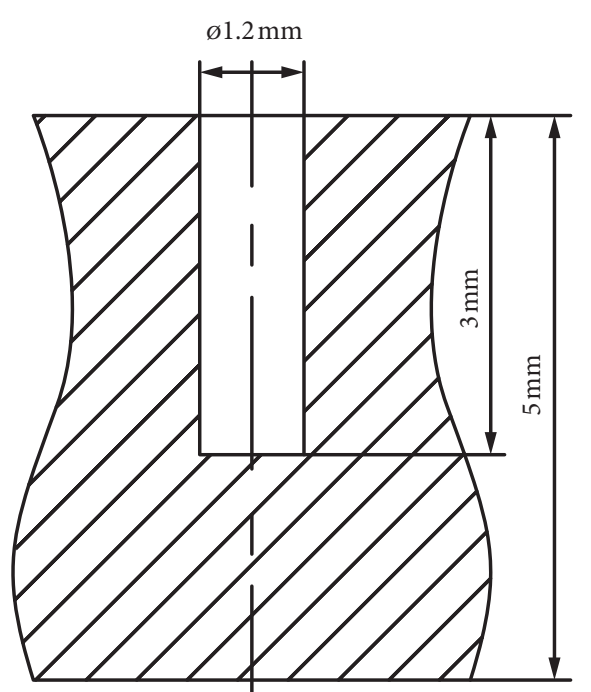

(a)

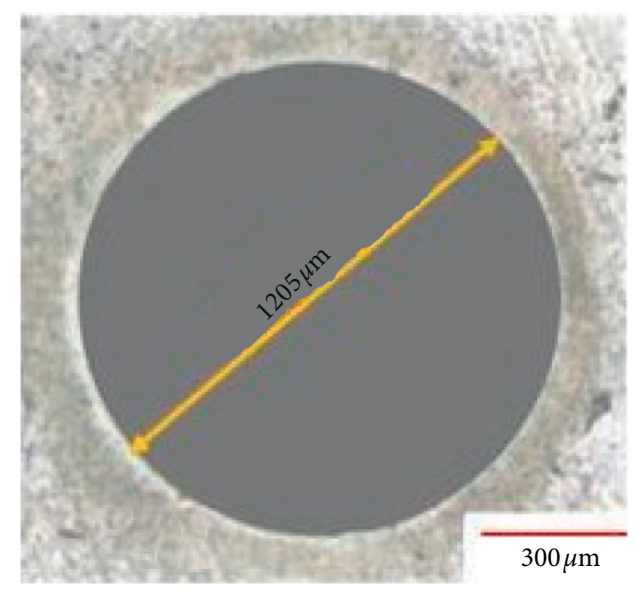

(b)

FIgURE 2: The microdie: (a) sectional view; (b) top view.

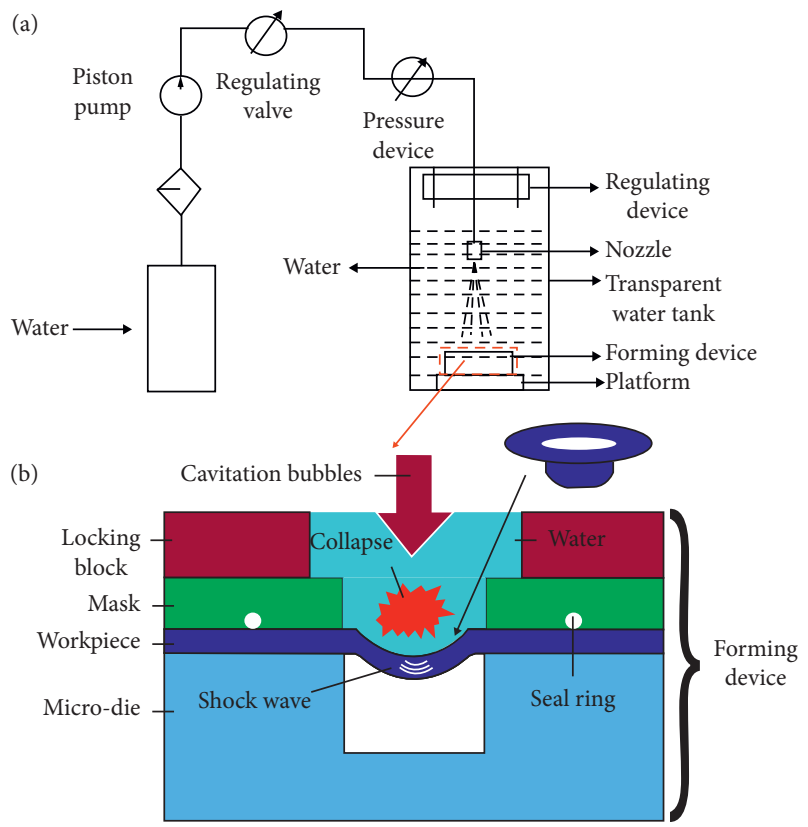

FIgURE 3: (a) The formation system of water-jet cavitation shock microforming; (b) cross-sectional side view.

sample material continues until the peak stress falls below the dynamic yield strength. In this study, a cavitation nozzle was used to generate cavitation bubbles.

2.5. Characterization Procedure. The forming properties of the metal foils were characterized after the water-jet cavitation shock microforming experiment. The KEYENCE VHX-1000C digital microscope was used to measure the three-dimensional (3D) profile and the forming depth of the formed parts. A confocal laser-scanning microscope (Axio CSM 700) was utilized to observe the surface morphology and roughness. The deformation region of the section hardness distributions of formed components was measured by the micro-Vickers hardness tester.

\section{Results and Discussion}

3.1. Forming Depth. The depth of the forming components of formed parts is very important in terms of the surface quality of forming properties. The forming depths, which were defined as the depths of the maximum deformation of formed components, were characterized by a digital microscope (KEYENCE VHX-1000C). The incident pressure for the forming depth was $20 \mathrm{MPa}$ as shown in Figure 4. The forming depth and the three-dimensional (3D) profile of 304 stainless steel foil formed components are shown in Figure 4(a). This showed that the metal foils attained good geometrical features under this dynamic microforming method, indicating that strong plastic deformation occurred during the process. Figure 4(b) shows the forming depth, which indicated that the cross-sectional measurement shows a smooth profile with no unexpected changes, indicating that the formed parts move into the die consistently during the process of shock forming. The maximum forming depth of the formed part reaches $327.8 \mu \mathrm{m}$ and was situated at the center of the formed part.

The forming depth of the formed components with different incident pressures is shown in Figure 5. The results indicated that, as the incident pressures increased from $8 \mathrm{MPa}$ to $20 \mathrm{MPa}$, the forming depth of the 304 stainless steel components increased quickly from $124.7 \mu \mathrm{m}$ to $327.8 \mu \mathrm{m}$. This shows that higher incident pressures produce higher forming depth. Therefore, in order to fully deform the 304 stainless steel foil, higher pressure is essential and this phenomenon can be interpreted by that higher incident pressure generates stronger collapse bubbles which exert on the surface of the material. Acting on the surface of the sample, high-pressure shock waves propagate into the interior of the sample. Due to the constrain of the locking 

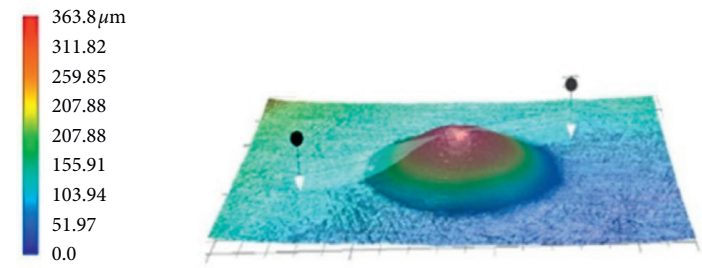

(a)

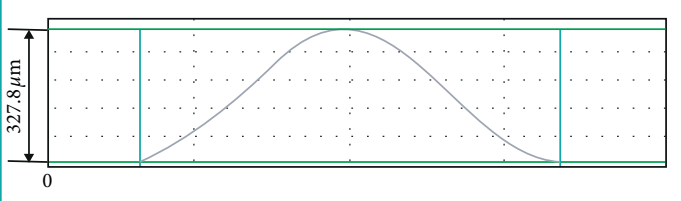

(b)

FIgURE 4: Three-dimensional (3D) profile and forming depth of the formed part.

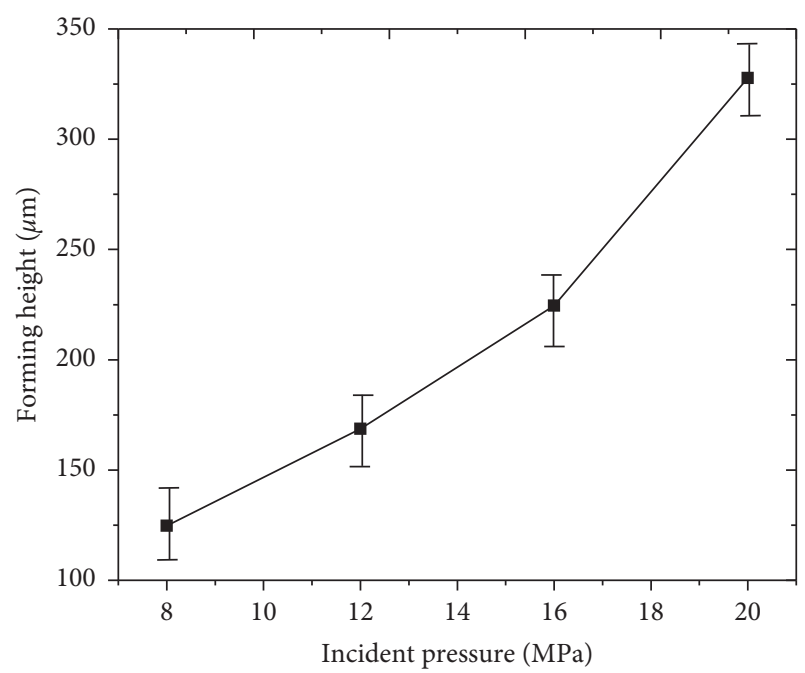

Figure 5: Influence of incident pressure on forming depth.

block, the part of the sample material outside of the die cannot flow into the die and when the incident pressure increased, sample material inside the die suffered greater deformation, hence increased the forming depth. In other words, when the incident pressure is very high, unwanted defects such as fracture may occur. Such defects such as fracture arise when the incident pressure on the sample approaches its forming limit. Hence, in this process the incident pressure should not be less than $8 \mathrm{MPa}$ and not more than $20 \mathrm{MPa}$. In addition, when the incident pressure is below $8 \mathrm{MPa}$, there will be a little or no forming at all. This makes the forming less effective.

3.2. Surface Quality. The forming region surface would generate a very minor microscopic geometry, the microstructures on the die are obviously replicated onto the sample, and this makes the surface roughness of formed components increase, no matter the kind of forming methods used $[21,22]$ as shown in Figure 6. The mechanical properties of materials such as corrosion resistance, fatigue strength, and abrasion resistance of the components are also significantly affected in terms of surface roughness. Therefore, it is very important to study the surface quality of the microcharacteristics in the water-jet cavitation shock microforming process. In addition, the impact of incident pressure on the surface quality of samples is value exploring. In this study, the Axio CSM 700 confocal laser- scanning microscope was used to measure the roughness values and observe the surface morphology of the forming parts. Figure 6 shows the bottom region of the forming parts with different incident pressures of the surface morphologies.

It was observed that the surface roughening displayed at the bottom region with a clear defect as the incident pressure increased. These occurrences could be attributed to the following reasons: (a) the surface becomes rough due to lack of restraints on the surface of the grain when the surface grain is prone to slip rotation as stated by the surface layer model; (b) another reason may be related to the surface roughness of the die, because the crater surface of the die used in the study was not ground. Friction is generated when the metallic foils get in contact with the die surface during the process of water-jet cavitation shock microforming affects the surface quality of the formed components. Therefore, the surface of the die should be ground to reduce the surface roughness of the material; (c) therefore, the surface quality of the formed component degraded during the plastic deformation of the sample where dislocation slip occurred that leaves the slip step on the surface of the material [23]; (d) also due to the erosive effect of the cavity, as a result of the impact of the surface of the metallic foil with the water jets resulting from the collapse of the bubbles, beyond the mechanical deformations determined by the mechanics of the forming. In order to further study, the impact of incident pressures on surface quality and the measurement of surface roughness should be considered. The surface roughness value $(\mathrm{Ra})$ can signify the roughening behavior of the sample which is widely applied in industries [24]. Therefore, the Ra value of the bottom region was attained with a confocal microscope, as shown in Figure 7. This shows that as the incident pressure increased from $8 \mathrm{MPa}$ to $20 \mathrm{MPa}$, the Ra value only increased from $0.685 \mu \mathrm{m}$ to $1.159 \mu \mathrm{m}$, indicating that the surface roughness only increased slightly with the increase of the incident pressure. This type of forming could fully form the part and, at the same time, ensured that the surface quality is maintained. This means that the increase was not obvious.

3.3. Thickness Distribution. It is observed that deformation of material could cause localized necking and even fracture as a result of thinning of the formed components and deteriorates the mechanical properties. Therefore, the thickness distribution of formed components after water-jet 


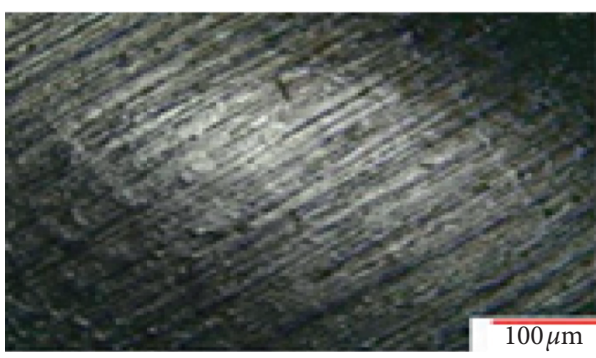

(a)

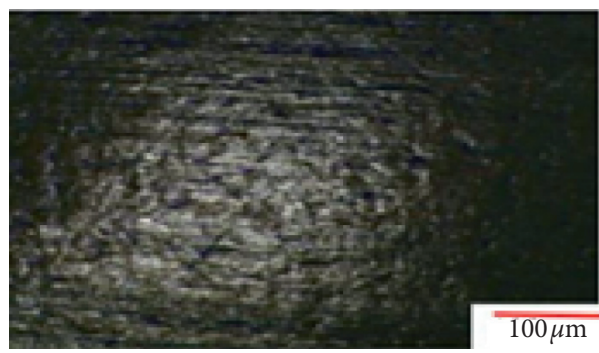

(c)

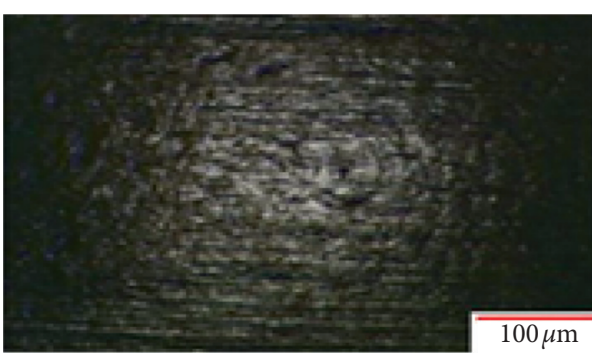

(b)

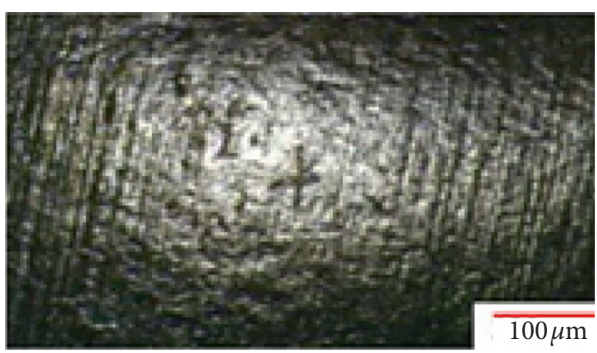

(d)

FIGURE 6: Surface morphology of the bottom region under different incident pressures: (a) $8 \mathrm{MPa}$; (b) $12 \mathrm{MPa}$; (c) $16 \mathrm{MPa}$; (d) $20 \mathrm{MPa}$.

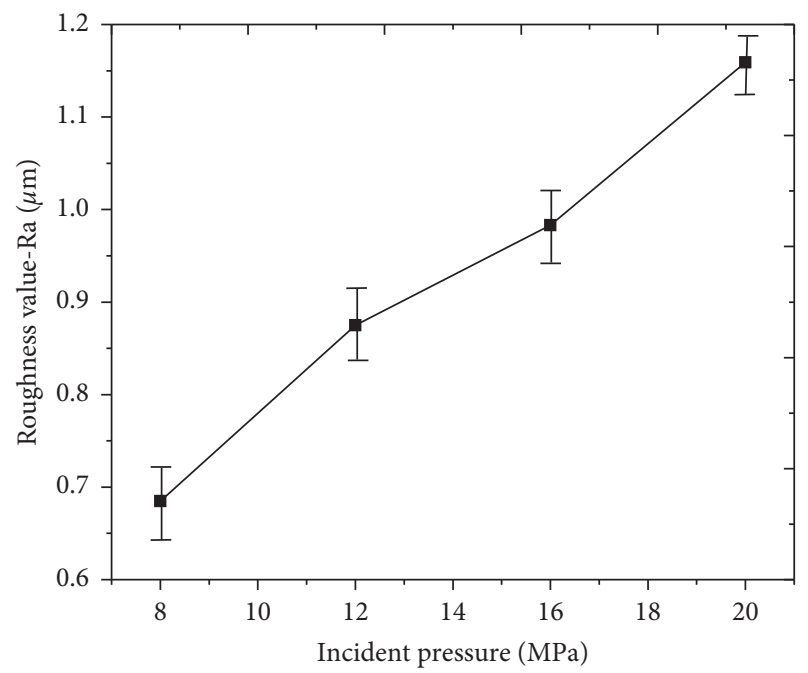

FIGURE 7: Surface roughness of formed components in the bottom region under different incident pressures.

cavitation shock forming was studied to evident the plastic deformation behavior of the sample. The material with a thickness of $100 \mu \mathrm{m}$ was studied with an incident pressure of $20 \mathrm{MPa}$. The formed components were put into a mold with a low viscosity epoxy resin. After seven hours, the sample was taken out, grinded, and polished by 80 \# to 7000 \# sandpaper. To characterize the distribution of thickness, the left thirteen (13) points were selected as shown in Figures 8 and 9 .

The original thickness $l_{o}$ of each 304 stainless steel foil should be measured to certify the accuracy of the results. The thickness of each formed region was $l_{i}$. The thickness thinning ratio was mathematically calculated using equation (1), where $R$ is the thickness thinning ratio:

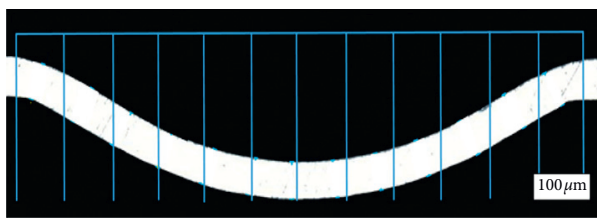

Figure 8: Selection of measurement location.

$$
R(\%)=\frac{l_{o}-l_{i}}{l_{o}} \times 100 \% .
$$

Figure 10 shows the distribution of the thickness thinning rate with different incident pressures. This shows that thickness thinning rate increases with the incident pressure. The maximum thickness thinning rate of the formed foils was $21.27 \%$ with the incident pressure of $20 \mathrm{MPa}$ and $14.13 \%$ with the incident pressure of $8 \mathrm{MPa}$. Therefore, it could be seen that the thickness thinning rate increased with the increase of the incident pressure. In addition, Figure 10 shows that from the fillet region to the transition region, the thickness thinning ratio of the sample is almost decreasing under different incident pressures. This is because from the fillet to the transition region of the metal foil, the stress value of the foil decreases without the die constraint, so that the thickness thinning ratio declines. However, irregular thickness distribution was observed from the transition region to the bottom region of the sample. This is due to the inhomogeneous deformation of the sample. When the incident pressure was $20 \mathrm{MPa}$, the thickness of the sample gradually increases from the transition region to the bottom region. This was because under the high incident pressure, the shock waves induced by collapse of cavitation bubbles were stronger and resulted in deeper forming depth. The compressive stress acting on the center of the sample was 


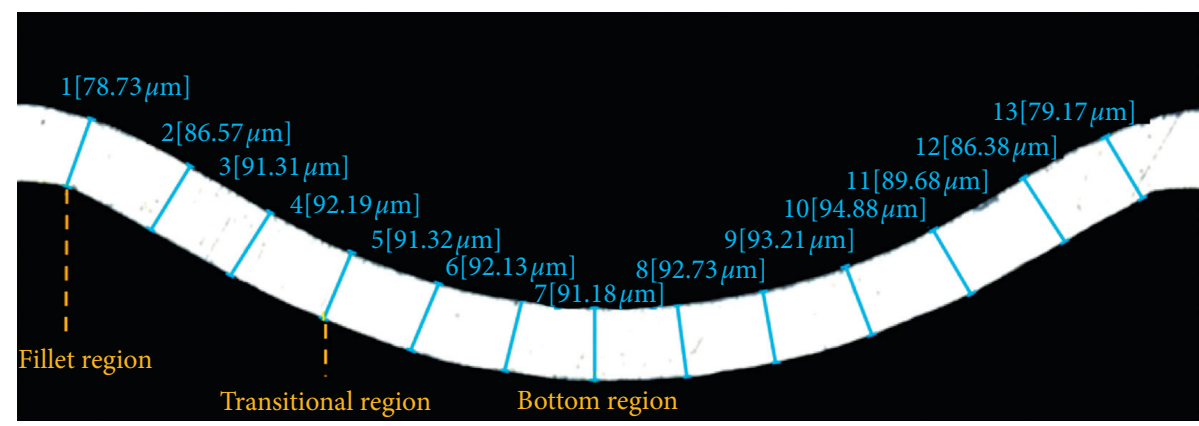

Figure 9: Thickness measurements of a material thickness of $100 \mu \mathrm{m}$ at $20 \mathrm{MPa}$ incident pressure.

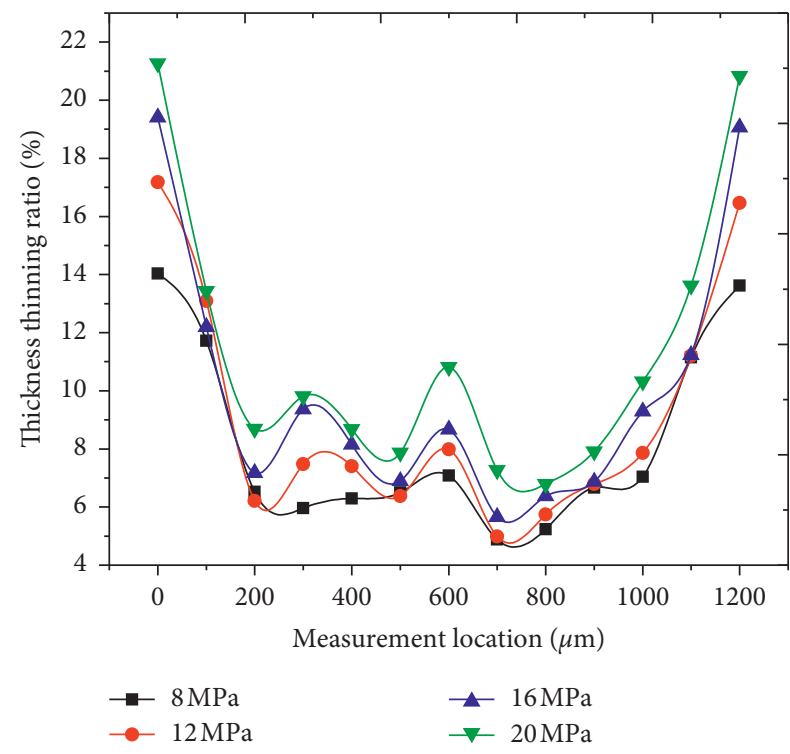

FIgURE 10: Distribution of thickness thinning ratio.

more pronounced, which is the main reason for the evident thinning of the bottom region. Also, the thickness thinning ratio on both sides varies a little at the same incident pressure as seen in Figure 10. Significantly, another advantage with water-jet cavitation shock microforming is the increase in uniformity of thickness distribution. The above study results show that the water-jet cavitation shock microforming technology can improve the thickness thinning during the forming process and obtain uniform thickness distribution using 304 stainless steel foils.

3.4. Microhardness Distribution. This part describes utilizing the micro-Vickers hardness tester to test for the sectional distribution of the formed components produced by a water jet with different incident pressures. Under this study, the maximum load used was $10 \mathrm{~g}$ which was retained for $15 \mathrm{~s}$ when the loading force was attained and unloaded. Figure 11 shows locations of five different points which were measured. The mechanical properties of the materials play a very important role in hardness. The characterization of this parameter assures the ability of materials to the resistance of hard materials from forcing into its surface; therefore, this can resist elastoplastic deformation and wear of the material.

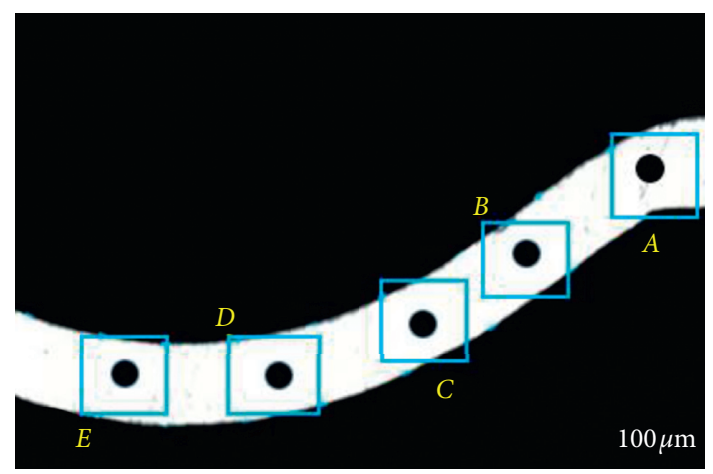

FIGURE 11: Measurement locations of microhardness.

The local hardness of the material would be increased by the plastic deformation which will cause work hardening; therefore, high local hardness is generated with higher plastic deformation [25].

The measurement of blank sample hardness was conducted. Figure 12 shows the results hardness of formed parts. Therefore, irregularity was presented after the hardness test of the formed component when incident pressure was $8 \mathrm{MPa}$. Comparatively, the hardness at the fillet region was reduced and the increase in hardness at additional locations was a bit visible when the incident pressure was $20 \mathrm{MPa}$. This occurred as a result of the sample being at the cold-rolled state. There were numerous dislocations in the sample such as dislocation wall, dislocation line, and dislocation twins. In the process of water-jet cavitation shock microforming, the influence of shock waves on microstructure becomes problematic in reflection to the change in microhardness during the propagation of shock waves into the sample. Clearly, the hardness never changed.

In order to determine whether or not the 304 stainless steel foil at it cold-rolled state caused the above phenomena, the 304 stainless steel foil was annealed at a temperature of $650^{\circ} \mathrm{C}$ used in an incident pressure of $20 \mathrm{MPa}$. Five different locations were selected and measured as shown in Figure 11. The results of the hardness are shown in Figure 13. The hardness of the water-jet regions increased due to the 304 stainless steel was annealed at a required temperature. In the initial process, the grain melted, then afterwards there was a continuous growth in the new grain until the initial deformation disappeared completely, and this decreased the 


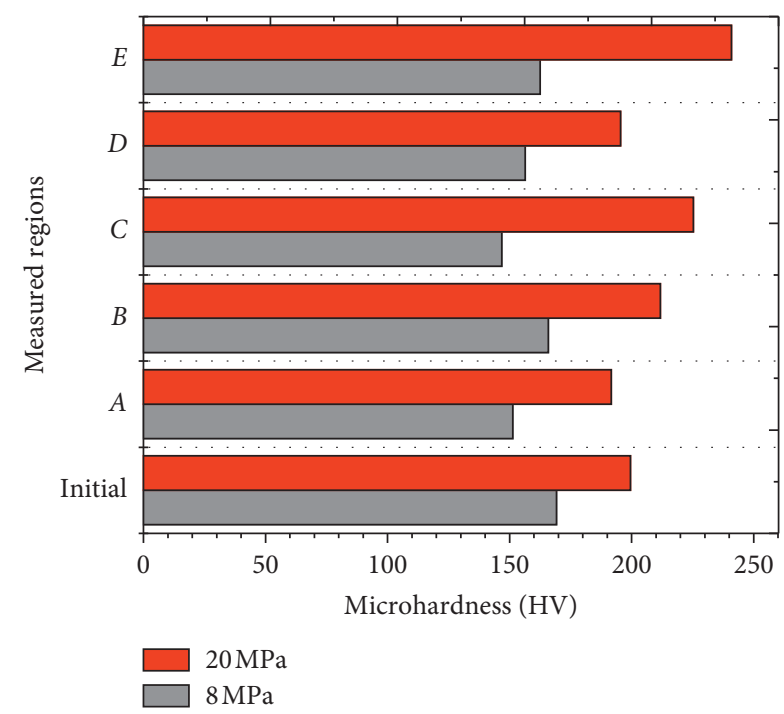

FIGURE 12: Microhardness distribution of the formed component in the cold-rolled state.

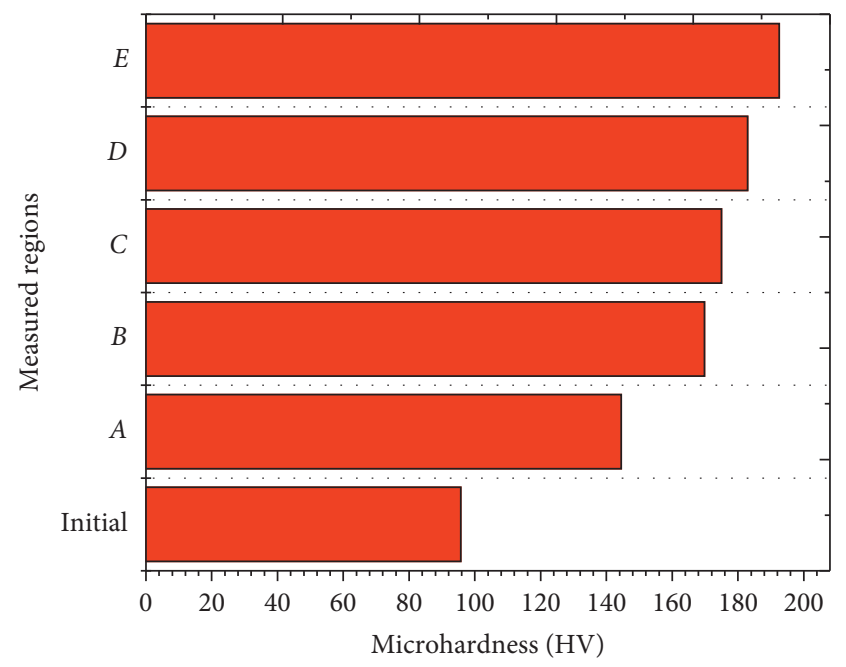

FIGURE 13: Microhardness distribution of the formed component in the annealed state.

residual stress inside the material. The defects that existed in the sample were few which indicated that the material organization was uniform and the hardness of the sample could be reflected by the water-jet shock.

\section{Conclusions}

Due to the continuing trend of miniaturization, new costefficient and flexible methods for processing small parts are required. Therefore, this paper presents a novel water-jet forming technology for the fabrication of 304 stainless steel foils. Through this experimental process, the forming depth, surface quality, thickness distribution, and section hardness distributions were investigated under different incident pressures $(8 \mathrm{MPa}-20 \mathrm{MPa})$. The following conclusions were drawn after the study:
(1) The forming depth increased from $124.7 \mu \mathrm{m}$ to $327.8 \mu \mathrm{m}$ as the incident pressure increased from $8 \mathrm{MPa}$ to $20 \mathrm{MPa}$.

(2) The surface roughness increased from 0.685 to 1.159 as the incident pressure increased from $8 \mathrm{MPa}$ to $20 \mathrm{MPa}$. Hence, the surface roughness of the center region of the forming components gradually improved.

(3) The maximum thickness thinning ratio of the formed foils was $21.27 \%$ with the incident pressure of $20 \mathrm{MPa}$ and $14.13 \%$ with the incident pressure of $8 \mathrm{MPa}$. Therefore, this indicated that the thickness thinning ratio increased with the increase of the incident pressure.

(4) The tested hardness indicated that during the coldrolled state of the sample, the hardness of the sample increased slightly along the cross section of the formed region and the hardness of the annealed 304 stainless steel foils increased significantly along the cross-sectional region.

In general, the above conclusion indicated that water-jet cavitation shock microforming holds the advantages to produce microparts of thin metallic foils using different incident pressures and a microdie as a forming source.

\section{Data Availability}

The data used to support the findings of the study have not been made available because they are part of an ongoing project.

\section{Conflicts of Interest}

The authors declare that they have no conflicts of interest.

\section{Acknowledgments}

The authors are grateful to the project supported by the Jiangsu University, China, Natural Science Foundation of China (51575245), Major Research Program of Jiangsu Province (BE2016161), and Cultivation Project for Academic Leader of Jiangsu Province ([2014] 23), and the members of the cavitation research team in the Jiangsu Mechanical Department for the helpful comments on this work.

\section{References}

[1] Y. Ye, Y. Feng, Z. Lian, and Y. Hua, "Mold-free fs laser shock micro forming and its plastic deformation mechanism," Optics and Lasers in Engineering, vol. 67, pp. 74-82, 2015.

[2] X. Wang, K. Sun, Y. Ma, Z. Shen, F. Liu, and H. Liu, "Experimental investigation on laser shock micro hydraulic bulging of copper foil," Optics \& Laser Technology, vol. 115, pp. $390-397,2019$.

[3] A. Al-Tamimi, R. Darvizeh, and K. Davey, "Experimental investigation into finite similitude for metal forming processes," Journal of Materials Processing Technology, vol. 262, pp. 622-637, 2018. 
[4] D. Odhiambo and H. Soyama, "Cavitation shotless peening for improvement of fatigue strength of carbonized steel," International Journal of Fatigue, vol. 25, no. 9-11, pp. 1217$1222,2003$.

[5] H. Soyama, "Comparison between the improvements made to the fatigue strength of stainless steel by cavitation peening, water jet peening, shot peening and laser peening," Journal of Materials Processing Technology, vol. 269, pp. 65-78, 2019.

[6] M. Ijiri, D. Shimonishi, D. Nakagawa, and T. Yoshimura, "New water jet cavitation technology to increase number and size of cavitation bubbles and its effect on pure Al surface," International Journal of Lightweight Materials and Manufacture, vol. 1, no. 1, pp. 12-20, 2018.

[7] H. Soyama, "High-speed observation of a cavitating jet in air," Journal of Fluids Engineering, vol. 127, no. 6, 2005.

[8] M. Ijiri, D. Shimonishi, D. Nakagawa, and T. Yoshimura, "Evolution of microstructure from the surface to the interior of Cr-Mo steel by water jet peening," Materials Sciences and Applications, vol. 8, no. 10, pp. 708-715, 2017.

[9] T. Yoshimura, K. Tanaka, and N. Yoshinaga, "Nano-level material processing by multifunction cavitation," Nanoscience \& Nanotechnology-Asia, vol. 8, pp. 41-54, 2018.

[10] G. Q. Chen, D. Zhang, J. H. Song, Y. S. Zeng, Z. Q. Li, and W. L. Zhou, "Effect of high pressure waterjet peening on surface strengthening properties of 7075-T651 aluminum alloy," Key Engineering Materials, vol. 373-374, pp. 828-831, 2008.

[11] A. Azhari, C. Schindler, J. Nkoumbou, and E. Kerscher, "Surface erosion of carbon steel 1045 during waterjet peening," Journal of Materials Engineering and Performance, vol. 23, no. 5, pp. 1870-1880, 2014.

[12] M. Srivastava, S. Hloch, R. Tripathi et al., "Ultrasonically generated pulsed water jet peening of austenitic stainless-steel surfaces," Journal of Manufacturing Processes, vol. 32, pp. $455-468,2018$.

[13] S. Barriuso, M. Lieblich, M. Multigner, I. Etxeberria, A. Alberdi, and J. L. González-Carrasco, "Roughening of metallic biomaterials by abrasiveless waterjet peening: characterization and viability," Wear, vol. 270, no. 9-10, pp. 634-639, 2011.

[14] A. Azhari, C. Schindler, and B. Li, "Effect of waterjet peening on aluminum alloy 5005," The International Journal of Advanced Manufacturing Technology, vol. 67, no. 1-4, pp. 785795, 2012.

[15] T. Hashimoto, Y. Osawa, S. Itoh, M. Mochizuki, and K. Nishimoto, "Long-term stability of residual stress improvement by water jet peening considering working processes," Journal of Pressure Vessel Technology, vol. 135, 2013.

[16] A. Naito, O. Takakuwa, and H. Soyama, "Development of peening technique using recirculating shot accelerated by water jet," Materials Science and Technology, vol. 28, no. 2, pp. 234-239, 2012.

[17] P. K. Farayibi, T. E. Abioye, J. W. Murray, P. K. Kinnell, and A. T. Clare, "Surface improvement of laser clad Ti-6Al-4V using plain waterjet and pulsed electron beam irradiation," Journal of Materials Processing Technology, vol. 218, pp. 1-11, 2015.

[18] C. E. Brennen, Cavitation and Bubble Dynamics, Cambridge University Press, Cambridge, UK, 2014.

[19] K. Sato, S. Ohjimi, and Y. Sugimoto, "Collapsing and impulsive behavior of cavitation clouds on cavitating water-jet impinging on solid wall (fluids engineering)," Transactions of the Japan Society of Mechanical Engineers Series B, vol. 75, no. 750, pp. 241-250, 2009.
[20] S. Fujikawa and T. Akamatsu, "Experimental investigations of cavitation bubble collapse by a water shock tube," Bulletin of JSME, vol. 21, no. 152, pp. 223-230, 1978.

[21] X. Wang, L. Li, Z. Shen et al., "Experimental investigation on: laser shock micro-forming process using the mask and flexible pad," Optics and Lasers in Engineering, vol. 88, pp. 102-110, 2017.

[22] F. Luo, K.-H. Li, J.-M. Zhong, F. Gong, X.-Y. Wu, and S.-C. Ruan, "An ultrasonic microforming process for thin sheet metals and its replication abilities," Journal of Materials Processing Technology, vol. 216, pp. 10-18, 2015.

[23] S. Solhjoo, P. J. Halbertsma, M. Veldhuis, R. Toljaga, Y. Pei, and A. I. Vakis, "Effects of loading conditions on free surface roughening of AISI 420 martensitic stainless steel," Journal of Materials Processing Technology, vol. 275, Article ID 116311, 2020.

[24] R. K. Thakur, D. Sharma, and K. K. Singh, "Optimization of surface roughness and delamination factor in end milling of graphene modified GFRP using response surface methodology," Materials Today: Proceedings, vol. 19, pp. 133-139, 2019.

[25] J. A. Del Valle, F. Carreño, and O. A. Ruano, "Influence of texture and grain size on work hardening and ductility in magnesium-based alloys processed by ECAP and rolling," Acta Materialia, vol. 54, no. 16, pp. 4247-4259, 2006. 